\title{
SUJEITO INFORMACIONAL, CONCEITO EM EMERGÊNCIA: uma revisão teórico-conceitual em periódicos Ibero-Americanos
}

\author{
INFORMATIONAL SUBJECT, CONCEPT IN EMERGENCY: \\ a theoretical-conceptual review of Ibero-American scientific journals
}

Ruleandson do Carmo ${ }^{1}$

Carlos Alberto Ávila Araújo²

\begin{abstract}
RESUMO
Revisa o emprego do conceito de sujeito informacional em artigos publicados nos periódicos científicos ibero-americanos do campo da Ciência da Informação (divulgados entre 2012 - ano da primeira publicação de artigo com tal definição encontrada - e março de 2018 - época da coleta de dados da presente pesquisa), disponíveis na plataforma do Portal de Periódicos da Coordenação de aperfeiçoamento de pessoal de nível superior - Capes. Conceitua sujeito informacional, revisitando, para tal, a origem da concepção de sujeito na Grécia Antiga, bem como definições de sujeito na filosofia e na psicanálise, problematizando a importância da ideia de sujeito para o pensamento científico. Avalia 0 uso do termo "sujeito informacional", bem como de outros usos e entendimentos do termo "sujeito" nos referidos periódicos. Conclui que 0 conceito de sujeito informacional emerge para responder à angústia de pesquisadores do campo da $\mathrm{Cl}$ insatisfeitos com o termo "usuários da informação", insuficiente para compreender as relações contemporâneas dos sujeitos com a informação em diversos contextos e formatos. Constata-se ainda, dentre outros, que se trata de concepção muito recente no supracitado campo, e, portanto, é percebida uma subutilização do termo "sujeito informacional" nos artigos estudados em comparação com o uso do termo tradicional "usuário da informação".

Palavras-chave: Sujeito informacional. Usuário da Informação. Estudos de usuários. Práticas Informacionais. Ciência da Informação.

\section{ABSTRACT}

This research aims to analyse the usage of the concept of informational subject in articles published in ibero-american scientific journals in Information Science field (published between 2012 - the first time an article was published with this definition - and March 2018 - time when the database was collected for the research), available at "Portal de Periódicos da Coordenação de Aperfeiçoamento de Pessoal de Nível Superior - Capes". It conceptualizes the informational subject and reviews the origen of the conception of subject in Ancient Greece, as well the definition of subject in Philosophy and Psycoanalysis, to search for the importance of the idea of subject for the scientific thought. It also analyses the usage of the term information user and how the other usages and understandings of subject in the journals. It concludes that the concept of informational subject rises to answer the necessity of researchers from Information Science who are dissatisfied with the term informational user, insufficient to understand the contemporary relationships of the subjects with the information in many contexts and means. It also verifies that it's a recently conception in the area and, because of it, it can be seem a underutilized use of the term informational subject in the articles analysed compared to the use of the traditional term informational user.
\end{abstract}

Keywords: Informational subject. Informational user. User studies. Information practice. Information science.

Artigo submetido em 12/01/2019 e aceito em 14/08/2019

1 Pesquisador do grupo Estudos em práticas informacionais e cultura do Programa de Pós-Graduação em Ciência da Informação da Universidade Federal de Minas Gerais, Brasil. ORCID https://orcid.org/0000-0001-7190-4056. E-mail: ruleandson@gmail.com

2 Docente permanente do Programa de Pós-Graduação em Ciência da Informação da Universidade Federal de Minas Gerais, Brasil. ORCID https://orcid.org/0000-0003-0993-1912. E-mail: casalavila@yahoo.com.br 


\section{INTRODUÇÃo}

Na Ciência da Informação - Cl, o sujeito costuma ser visto como cliente, de diversos ambientes informacionais, como ser funcionalizado, alguém que exerce uma função/ocupação profissional ou como perfil sociodemográfico, conjunto de características de quem lida com a informação, como idade, renda, escolaridade etc., excluindo, por vezes, sua dimensão enquanto sujeito em si. Assim, na busca pelo melhor entendimento da referida dimensão na $\mathrm{Cl}$, em especial na subárea de estudos de usos e usuários da informação, constata-se a cunhagem do termo sujeito informacional, ideia marcada por forte viés da abordagem social em tais estudos.

Ao analisar a condição do sujeito em relação à própria condição de sujeito, Descartes afirma: "penso, logo existo" (DESCARTES, 2001, p. 38). No contexto informacional, pode-se dizer que para existir é necessário produzir e consumir informação (RENDÓN-ROJAS e HERRERA DELGADO, 2010). Mas como entender a existência do sujeito e a relação dele com a informação em um mundo marcado por tantas tensões sociais e culturais que enredam a vida? Um dos principais problemas contemporâneos da $\mathrm{Cl}$ é encontrar teorias e métodos que permitam entender a complexidade do fenômeno informacional e de quem com ele se relaciona:

\footnotetext{
0 atual quadro teórico-metodológico do campo de estudos de usuários de informação apresenta-se limitado ao não considerar o sujeito como ser contraditório e, portanto, unidade do diverso. Os estudos tradicionais desconsideram a apropriação subjetiva da informação, objetivando o diagnóstico de uso das fontes e dos serviços de informação e desconsiderando as funções das organizações na estrutura social e na apropriação da informação pelos sujeitos (PINTO e ARAÚJ0, 2012, p. 225).
}

0 imbróglio fundamental das teorias e métodos tradicionais, para os autores, é a perda das subjetividades dos indivíduos e dos diversos elementos construídos socialmente por eles, pois tais indivíduos modificam a realidade social, em um movimento dialético entre indivíduo e realidade social. Para Araújo (2013), faz-se necessária uma abordagem contemporânea, caracterizada por perspectiva microscópica de análise, com aproximação compreensiva, marcada pela busca de significados. Nela, dá-se foco: a) ao caráter coletivo/intersubjetivo das ações dos sujeitos; e b) ao enraizamento de tais ações em contextos sócio-históricos definidos.

Com isso, a importância do contexto torna-se fundamental, pois significa que:

[...] a análise muda do cognitivo para o social e que, portanto, passa-se a considerar tanto as formas como o contexto [...] nas ações do indivíduo quanto como as ações do indivíduo são passíveis de alterar o contexto, num ciclo constante. Uma consequência disto é a adoção da terminologia práticas informacionais para denominar os estudos conduzidos a fim de investigar como se dão os inter-relacionamentos entre 0 sujeito e a informação (DUARTE; ARAÚJO; PAULA, 2017, p. 295). 
Em meio ao cenário de abordagem social dos estudos de usuários, o conceito de sujeitos informacionais pode ser visto como contraponto ao termo usuário da informação. A ideia pode ser referenciada a Rendón-Rojas e García Cervantes (2012), pois as buscas pelo termo no Portal de Periódicos da Coordenação de Aperfeiçoamento de Pessoal de Nível Superior - Capes ${ }^{3}$, no Google Acadêmico ${ }^{4}$ e no Sciel $0^{5}$, demonstram que a primeira definição do termo é registrada em artigo deles. Para os autores, o sujeito informacional é aquele que:

se constitui ao ter uma posição no espaço socioinformacional concreto, perante a reflexão, análise e atuação na estrutura social sob uma crítica profunda, sendo ele um agente de informação de conjuntura social, como quem realiza um ato político, para denunciar que o status-quo contemporâneo requer uma reestruturação; a partir do sentimento de comunidade e do reconhecimento do outro (RENDÓN-ROJAS; GARCÍA CERVANTES, 2012, p. 42, tradução nossa).

Além da divergência entre usuário da informação e sujeito informacional, outro conceito que se contrapõe a outro tradicional na $\mathrm{Cl}$ é o de práticas informacionais. A prática informacional é alternativa crítica à ideia de comportamento informacional, iniciado nos anos 1960 e popularizado nos anos 1990, mas, geralmente usado sem reflexão de que comportamento associa-se a à behaviorista Análise do Comportamento da Psicologia, concepção inadequada ao estudo da informação, constituinte das relações sociais (SAVOLAINEN, 2007).

Apesar da emergência do conceito sujeito informacional - no universo desta pesquisa recuperase 0 termo somente em artigo de 2012 - e 0 conceito de prática informacional ser demarcado nos anos 1960, segundo Savolainen (2007), percebe-se teórica e metodologicamente proximidades e adequações da ideia de sujeito informacional aos estudos das práticas informacionais, pois ambos se focam nos aspectos sociais, culturais, históricos e relacionais.

Tensões entre sujeito, usuário, comportamento e prática ocorrem na $\mathrm{Cl}$ em diversas partes do mundo. Uma de tais partes é a Ibero-américa, formada por pelo menos $22^{6}$ países de língua espanhola e portuguesa da Península-Ibérica, no sudoeste da Europa (Andorra, Espanha e Portugal), e da América Latina (Argentina, Bolívia, Brasil, Chile, Colômbia, Costa Rica, Cuba, El salvador, Equador, Espanha,

3 http://www.periodicos.capes.gov.br/

4 https://scholar.google.com.br/

5 www.scielo.org/php/index.php

6 Não foi encontrado consenso acerca dos países que compõem a Ibero-América. A Organização dos Estados Ibero-americanos para a Educação, a Ciência e a Cultura - OEI considera 24 países, dois a mais do que a Segib, a Guiné Equatorial, na África, e Porto Rico, na América do Norte (OEI, 2018). 
Guatemala, Honduras, México, Nicarágua, Panamá, Paraguai, Peru, Portugal, República Dominicana, Uruguai e Venezuela) (SEGIB, 2018).

Para Araújo (2018), a reflexão acerca das pesquisas em Cl na lbero-américa é imprescindível, pois, em quase todos os países, o ensino nos níveis de graduação e de pós em $\mathrm{Cl}$ apresentam conceitos e/ou correntes teóricas centradas mais na perspectiva da information science dos EUA. 0 resultado é a pesquisa mundial em $\mathrm{Cl}$ ser comumente conduzida a partir de materiais estadounidenses e anglo-saxões. Uma das principais particularidades da pesquisa ibero-americana em $\mathrm{Cl}$ é a crítica aos modelos funcionalistas, comuns nos EUA.

Assim, se "reproduz-se uma lógica de invisibilidade e exclusão que tem como resultado a perda de oportunidade do incremento da formação dos futuros pesquisadores e profissionais" (ARAÚJO, 2018, p. 44), lógica que minimiza as possibilidades de contribuição da Ibero-América para o avanço da Cl planetária, mesmo que a região possua iniciativas de integração nas dimensões histórica, cultural, política e econômica como a Asociación de Educación e Investigación en Ciencia de la Información de Iberoamérica y el Caribe, criada em 1996.

Mediante o referido cenário conceitual e científico exposto, objetiva-se aqui a revisão teóricoconceitual do termo sujeito informacional, publicado em periódicos científicos ibero-americanos, disponíveis no Portal de periódicos da Capes, para entender como os sujeitos informacionais têm sido entendidos e estudados na Cl Ibero-americana.

\section{SUJEITO}

Ainda que o presente artigo não objetive discutir o uso do termo sujeito por todos os campos do conhecimento, ressalta-se que a palavra sujeito é derivada do latim subjectus e do grego hypokeimenon (SUJEITO, 1998; HERNÁNDEZ-PACHECO, 2003; PREUS, 2007). 0 significado básico da palavra, dentro do entendimento pertinente ao presente estudo, é:

\footnotetext{
s.m. [substantivo masculino] 1. Pessoa, indivíduo, homem [...] 5. Pessoa ou indivíduo que se nomeia [...] Filos. [filosofia] Ser individual e real, suposto na base de todo pensamento (análogo à consciência), face ao qual o conteúdo de seu pensamento e 0 mundo exterior constituem um objeto [...] Lóg. [lógica] Na lógica tradicional, aquilo a que é reportado um predicado ou um atributo (SUJEITO, 1998, p. 5529).
}

Apesar de diversos autores definirem sujeito, apresenta-se aqui definições clássicas relacionadas por similaridades à ideia de sujeito informacional. Dito isso, traz-se as definições de sujeito em quatro autores: Aristóteles (2002), Descartes (1979), Kant (2001) e Lacan (1988). 
Na Grécia Antiga - período entre o século XX a. C. e o século IV a. C. (PILETTI e ARRUDA, 2007) -, considerada berço do pensamento ocidental, o conceito de sujeito é criado por Aristóteles 384 a. C./322 a. C. - (HERNÁNDEZ-PACHECO, 2003), na obra Metafísica, compilada no século IV a.C., por meio do termo hypokeimenon: sujeito ou algo subjacente - no sentido do que existe por baixo da superfície -; refere-se ao substrato final do ser, tudo o que permanece mesmo após mudanças radicais da matéria ou corpo físico; é a personalidade ou a essência do ser (ARISTÓTELES, 2002; HERNÁNDEZPACHECO, 2003; PREUS, 2007).

Apesar de a ciência ser um advento moderno, datado do séc. XVII d. C., e o conceito de sujeito ter origem em Aristóteles no séc. IV a. C., a noção de sujeito ganha força em um momento de angústia na história do pensamento, quando há uma crise de grande magnitude. Tal crise é o início da separação entre filosofia e ciência moderna, gerando considerável incerteza em relação a um mundo até então compreensível, mas que se modifica em sua forma de ser compreendido. Assim, a gênese da referida angústia faz por emergir 0 conceito de sujeito. Mediante tal crise, Descartes - 1596/1650 - define o cogito, com a célebre frase "cogito, ergo sum" - cuja tradução literal é "penso, logo sou, na qual o filósofo francês, tendo a dúvida como método, torna o sujeito substância consistente, formada pela união do ser pensante com o ser material, mas existente para além do pensamento do ser por meio de Deus (ELIA, 2010):

\footnotetext{
Pela primeira vez na filosofia, o discurso do saber se volta para o agente do saber, permitindo tomá-Io, ele próprio, como questão de saber. Pela primeira vez não se tratava apenas de situar os seres, de pensá-los através de uma ontologia, de uma metafísica, mas de colocar em questão o próprio pensar sobre o ser, que se torna, assim, também pensável. 0 sujeito se desdobra, movimento pelo qual se coloca no ato de conhecer, é suposto a este ato, mas não mais como mero correlato do objeto conhecido (ELIA, 2010, p. 13).
}

Para Elia (2010), um século após o sujeito como substância consistente em Descartes (1979), é Kant - 1724/1804 - quem o torna o sujeito transcendental, ao introduzir a razão na reflexão acerca do sujeito, fazendo dele um vazio. Em Kant (2001), o sujeito é transcendental, existente antes de qualquer experiência - única capaz de preencher o vazio do sujeito.

Considerável tempo após a definição de sujeito em Aristóteles (2002), em Descartes (1979) e em Kant (2001), o conceito de sujeito ganha o estatuto de discussão central na Psicanálise, sendo que a nuança de sujeito ganha instituto de conceito, na área, por meio do pensamento de Lacan 1901/1981 -, sendo, assim, o sujeito um conceito lacaniano, pois Freud não o desenvolve de forma direta (ELIA, 2010; BARROSO, 2012). Para Lacan (1988), o sujeito se constitui pela linguagem e é 0 efeito da articulação da linguagem, de materiais simbólicos: 
0 importante, para nós, é que vemos aqui o nível em que -antes de qualquer formação do sujeito, de um sujeito que pensa, que se situa aí -isso conta, é contado, e no contado já está o contador. Só depois é que o sujeito tem que se reconhecer ali, reconhecer-se ali como contador (LACAN, 1988, p. 26).

Assim, o sujeito em Lacan (1988) e na psicanálise, em geral, é um sujeito social, constituído em sua articulação por meio da linguagem no plano social, pois o sujeito só pode ser considerado ser humano por meio da ordem social, na qual percebe uma realidade, que só existe como realidade enquanto a realidade de e para um sujeito (ELIA, 2010). Assim, Lacan (1988), com forte influência de Freud, coloca conceitualmente o sujeito na centralidade da Psicanálise, mas contribui para definições do sujeito no pensamento/olhar científico em geral:

0 sujeito é um operador que se impõe a nós, desde que nos coloquemos em determinada perspectiva, em determinado lugar a partir do qual interrogamos a experiência humana [...] 0 sujeito é, portanto, sempre suposto. Não o encontramos na realidade, mas o supomos. Ou melhor, somos forçados a supô-lo a partir do momento em que reconhecemos a incidência do significante na experiência humana, esse átomo de simbólico que, por não ter em si mesmo significação alguma, convoca, no ser vivo, quando ele é falante (ou seja, quando é habitado pelo simbólico), a resposta que se chama de sujeito. Somos forçados a supor o sujeito quando reconhecemos 0 significante porque na verdade é 0 significante (e não nós) quem supõe 0 sujeito. 0 sujeito é, pois, uma suposição do significante, que se impõe a nós (ELIA, 2010, p. 70).

Portanto, o sujeito só existe na $\mathrm{Cl}$ devido à busca pela compreensão do sujeito pelo prisma científico informacional, prisma que o constitui/pressupõe como sujeito informacional.

\section{SUJEITO INFORMACIONAL}

Tradicionalmente, na Cl, o sujeito em contato com a informação é entendido como usuário da informação: inicialmente, usuário-público, com características sociodemográficas, interage com dado sistema ou serviço de informação; posteriormente, é central o entendimento do sujeito por meio de um tripé necessidade-busca-uso (PINHEIRO, 1982; LE COADIC, 1996). Por tal tripé, o usuário é um sujeito que, por uma necessidade informacional, converte-se em usuário da informação, ao lidar com a informação (NÚÑEZ PAULA, 2004, p. 24). Mas, tais entendimentos enfrentam críticas no campo. Duas das mais fortes são as de Day (2011) e Réndon-Rojas e García Cervantes (2012), na qual emerge o termo sujeito informacional.

Para Day (2011), é preciso demarcar a morte do termo usuário da informação, pois ele é teoricamente inadequado para a compreensão dos aspectos sociais, culturais e físicos dos indivíduos e das relações dos sujeitos com os afetos e poderes de tais aspectos. Além disso, ao pensar em 
usuário da informação, segundo o autor, foca-se em determinar causas e efeitos durante o processo de busca por informação. Assim, é preciso, mais do que isso, "visualizar sujeitos e objetos como coemergências mediadas através de co-determinações contextuais e por meio de zonas comuns de afetos mútuos [relacionais]" (DAY, 2011, p. 86, tradução nossa).

Neste contexto das problemáticas apontadas por Day (2011), abordagens em ascensão nas pesquisas em $\mathrm{Cl}$, entendem os usuários enquanto sujeitos informacionais: basicamente, sujeitos sociais que mantém relações com a informação, de acordo com Araújo (2013). Apesar da emergência dos sujeitos informacionais, o estudo da relação sujeitos-informação é sempre objeto da $\mathrm{Cl}$, sendo que o que diferencia os estudos é o modo como tais sujeitos serão analisados pelas pesquisas a partir de diversas abordagens, que buscam o entendimento dos indivíduos sob o ponto de vista de variados objetos empíricos da área. Uma de tais abordagens é a abordagem sociológica, que entende o sujeito como sujeito informacional (ORTEGA, 2012).

Segundo Araújo (2013), considerar como sujeito informacional o indivíduo antes visto apenas como usuário da informação, faz-se imprescindível ao estudo social da informação, pois consiste em duas importantes perspectivas: (a) considerar que o uso da informação só se dá por meio da aplicação, por parte dos sujeitos, de significados construídos coletivamente e (b) entender que os significados ou referências sociais construídas coletivamente pelos sujeitos ocorrem somente por meio das ações sociais. Somente assim, o anteriormente entendido apenas como usuário da informação pode ser entendido como sujeito informacional.

Deste modo, 0 aspecto informacional é o que diferencia o estudo social dos sujeitos na $\mathrm{Cl}$, os observando enquanto sujeitos que se relacionam com a informação, "sujeito sociais que atuam sobre o conhecimento para gerar, receber, transferir, construir e socializar a informação" (FREIRE; AQUINO, 2000, p. 72). É pela socialização da informação que o sujeito faz a mediação do real, real que só existe por meio da informação, informação que, por sua vez, media tanto as transações intersubjetivas quanto a auto-identidade do sujeito (DAY, 2014; RÉNDON-ROJAS e GARCÍA CERVANTES, 2012).

A relação entre sujeito e objeto informacional é a premissa para se entender o sujeito informacional, de acordo com Rendón-Rojas e García Cervantes (2012): na sociedade contemporânea, há aumento das tensões e desigualdades sociais, fazendo com que os sujeitos se confrontem e se articulem social, política e culturalmente com múltiplos discursos de diferentes contingências sociais, tomando escolhas para, por meio da informação, constituírem-se enquanto sujeitos, participarem socialmente e construírem identidades culturais autônomas: 
É neste contexto que se dá a emergência do sujeito informacional, em um cenário que condiciona, mas ao mesmo tempo permite ao sujeito interpelar para demandar, construir e articular novas estruturas socioinformativas, para atuar nessa conjuntura social. Perante este fenômeno social, se reafirma que as identidades não se impõem, se constroem; são produto das relações sociais complexas (RENDÓN-ROJAS e GARCÍA CERVANTES, 2012, p. 36-37, tradução nossa).

Nesta perspectiva social, surgem os estudos das práticas informacionais, pouco usados no campo da $\mathrm{Cl}$, mesmo nascidos nos anos 1960, assim como o comportamento informacional (SAVOLAINEN, 2007). Para Araújo (2007; 2013), o conceito de prática informacional permite estudar sujeitos considerando facetas sociais da produção de conhecimento e é oriundo da ideia de prática da etnometodologia - estudo de métodos pelos quais indivíduos dão sentido às ações.

Deste modo, Savolainen (2007) diz que "comparado com o modelo de comportamento informacional, o conceito de prática informacional adota como papel central os aspectos sociais e culturais enquanto fatores determinantes e qualificantes da busca por informação e compartilhamento de informação pelos sujeitos" (SAVOLAINEN, 2007, p. 125, tradução nossa), enquanto o comportamento informacional entende o lidar com a informação como sendo desencadeado por motivos e necessidades.

Apresentadas as definições e associações teóricas relacionadas ao conceito de sujeito informacional, traça-se a metodologia desenhada nesta pesquisa para alcance 0 objetivo central - 0 estudo do emprego do termo sujeito informacional em periódicos ibero-americanos.

\section{METODOLOGIA}

0 presente estudo exploratório de natureza qualitativa realiza-se nas seguintes etapas:

1) revisão teórico-conceitual dos conceitos de sujeito e de sujeito informacional;

2) levantamento (mar. 2018), do uso do termo sujeito informacional em artigos publicados em periódicos científicos da $\mathrm{Cl}$, disponíveis no Portal de Periódicos da Capes, realizado assim:

a) acesso à opção "Buscar periódico" do Portal, com a aplicação de filtro por área do conhecimento, limitando a listagem aos periódicos vinculados à $\mathrm{Cl}$, totalizando 399 periódicos;

b) consulta ao site de cada periódico e/ou ao International Standard Serial Number - ISSN ${ }^{7}$, para identificação do país de publicação do periódico e agrupamento dos pertencentes à Ibero-

$\overline{7 \text { http://issn.org }}$ 
américa, totalizando 48 periódicos. Considera-se 45 periódicos $^{8}$, visto que dois se repetem ${ }^{9}$ na listagem do referido Portal (por mudança de título, mas com os mesmos artigos disponíveis no repositório virtual de ambos) e um periódico ${ }^{10}$ não apresenta os artigos online. Assim, a amostra extraída do referido Portal é de 45 periódicos de nove dos 24 países da Ibero-América - Argentina (um), Brasil (31), Colômbia (um), Cuba (dois), Espanha (cinco), México (um), Peru (um), Portugal (um) e Venezuela (dois). Estatisticamente, 12\% ou 48 periódicos entre 399 são publicadas na Ibero-América, com representação de 37,5\% ou nove dos 24 países da região.

c) consulta ao repositório virtual de cada um dos periódicos, da edição mais antiga disponibilizada por cada um (1972 - Ciência da Informação ISSN - 0100-1965) até a edição mais recente, acessível na data da referida pesquisa (mar. 2018), buscando-se pelos termos - no singular e no plural - em português, em inglês e em espanhol: "usuário da informação" ("information user", "usuario de la información”), "sujeito" ("subject", "sujeto”) e "sujeito informacional" (“informational subject”, "sujeto informacional”). Encontra-se, no repositório virtual dos 45 periódicos em estudo, 2.432 artigos que citam o termo "usuário da informação", 836 artigos que citam o termo "sujeito" (dissociado do termo sujeito informacional) e cinco que citam 0 termo "sujeito informacional". Avaliando-se tais resultados, bem como pesquisas pelo termo sujeito informacional no Google Acadêmico e no Scielo, percebe-se que a primeira citação ao termo sujeito informacional é encontrada no periódico Encontros Bibli - ISNN 1518-2924, v. 17, n. 33, publicado em jan. 2012, referindo-se ao quadrimestre jan./abr. (RENDÓN-ROJAS;

8 Apresenta-se os periódicos no formato título, ISSN, país: Información, cultura y sociedade, 1514-8327, Argentina; Revista interamericana de bibliotecología, 0120-0976, Colômbia; Acimed, 1024-9435, Cuba; Ciencias de la información, 0864-4659, Cuba; BiD. Textos universitaris de biblioteconomia i documentación, 1575-5886, Espanha; Documentación de las Ciencias de la Información, 02104210, Espanha; El Profesional de la información, 1386-6710, Espanha; PASOS: Revista de Turismo y Patrimonio Cultural, 1695-7121, Espanha; Revista General de Información y Documentación, 1132-1873, Espanha; Ingeniería, investigación y tecnología, 1405-7743, México; Alfa-Redi, 1681-5726, Peru; Enl@ce Revista Venezolana de Información, Tecnología y Conocimiento, 1690-7515, Venezuela; Opción, 1012-1587, Venezuela; Acervo, 0102-700X, Brasil; Arquivística.net, 1808-4826, Brasil; Biblios, 1562-4730, Brasil; Biblos, 0102-4388, Brasil; Ciberlegenda, 1519-0617, Brasil; Ciência da Informação, 0100-1965, Brasil; Datagramazero, 1517-3801, Brasil; Diálogo com a Economia Criativa, 2525-2828, Brasil; Em Questão, 1807-8893, Brasil; Encontros Bibli: revista eletrônica de biblioteconomia e ciência da informação, 1518-2924, Brasil; Estudos de literatura brasileira contemporânea, 1518-0158, Brasil; ETD. Educação Temática Digital, 1676-2592, Brasil; História, ciências, saúde-Manguinhos, 0104-5970, Brasil; InCID: Revista de Ciência da Informação e Documentação, 2178-2075, Brasil; iNfodesign, 1808-5377, Brasil; Informação Arquivística,2316-7300, Brasil; Informação \& informação, 1414-2139, Brasil; Informação \& Sociedade, 0104-0146, Brasil; Journal of Information Systems and Technology Management: JISTEM, 1809-2640, Brasil; Liinc em revista, 1808-3536, Brasil; Morpheus: Revista Eletrônica em Ciências Humanas, 1676-2924, Brasil; Morpheus: Revista Eletrônica em Ciências Humanas, 1676-2924, Brasil; Mouseion: revista do museu e arquivo histórico La Salle, 1981-7207, Brasil; Perspectivas em Ciência da Informação, 1413-9936, Brasil; Pesquisa Brasileira em Ciência da Informação e Biblioteconomia, 1981-0695, Brasil; RDBCI: Revista Digital de Biblioteconomia e Ciência Da Informação, 1678-765X, Brasil; Revista ACB, 1414-0594, Brasil; Revista Conhecimento em Ação, 2525-7935, Brasil; Revista CPC, 1980-4466, Brasil; Revista Electronica de Sistemas de Informaçao, ISSN1677-3071, Brasil; Revista Katálysis, 1414-4980, Brasil; e Transinformação, 0103-3786, Brasil.

9 Acimed, ISSN 1024-9435 (Cuba) e Acimed, ISSN 1561-2880 (Cuba), apesar de ISSNs diferentes, apresentam os mesmos artigos no repositório; ETD. Educação Temática Digital, ISSN 1676-2592 (Brasil) e Revista Online da Biblioteca Prof. Joel Martins, ISSN 1517-3992 (Brasil), apesar de ISSNs diferentes apresentam os mesmos artigos no repositório. IP, ISSN 1516-697X (Brasil). 
GARCÍA CERVANTES, 2012). Assim, em seguida, refina-se a busca, objetivando-se comparar e verificar o uso, no mesmo período histórico, dos termos usuário da informação, sujeito e sujeito informacional, em artigos pós-publicação do artigo de Réndon-Rojas e García Cervantes (2012), restringindo-se, assim, a pesquisa ao intervalo fev./2012 - mar./2018;

3) Análise qualitativa do emprego do termo sujeitos informacionais em comparação ao emprego do termo usuário da informação e do termo sujeito, com base nas teorias aqui apresentadas.

\section{APRESENTAÇÃO DOS RESULTADOS}

Após a coleta de dados, os artigos encontrados nos 45 periódicos ibero-americanos em estudo foram categorizados. Entre fevereiro de 2012, ano da primeira publicação de artigo com o termo sujeito informacional, e março de 2018, data da coleta de dados desta pesquisa, encontra-se: 901 artigos com citação do termo usuário, 261 artigos com citações ao termo sujeito e cinco artigos com citações ao termo sujeito informacional, especificamente. Inicialmente, em tal universo, percebe-se que o uso do termo usuário da informação é 180 vezes maior (901 artigos) do que o uso de sujeito informacional (cinco artigos)._Dentre os artigos com 0 termo sujeito e sujeito informacional, 266 ao todo, quantifica-se os empregos do conceito de sujeito na Tabela 1 e categoriza-se tais empregos conforme ilustra o Quadro 1.

Tabela 1 - Tipos de empregos do termo sujeito - 2012/2018

\begin{tabular}{lcc}
\hline \multicolumn{1}{c}{ Tipos de sujeitos } & $\mathbf{f}$ & $\%$ \\
Sujeito de forma genérica/sujeito de pesquisa & 227 & 85,38 \\
Discurso do sujeito coletivo & 12 & 4,51 \\
Sujeito social & 9 & 3,38 \\
Sujeito informacional & 5 & 1,87 \\
Sujeito cognoscente & 4 & 1,5 \\
Sujeito como oposição a usuário & 1 & 0,37 \\
Sujeito perfilado & 1 & 0,37 \\
Sujeito como indivíduo na Biblioteconomia, Arquivologia e & 1 & 0,37 \\
Museologia & & \\
Sujeito informativo & 1 & 0,37 \\
Modelo argumental do sujeito & 1 & 0,37 \\
Sujeito-arquivista & 1 & 0,37 \\
Sujeito qualificado (profissional) & 1 & 0,37 \\
Sujeito fonte e receptor & 1 & 0,37 \\
Sujeito da oração & 1 & 0,37 \\
\hline Total & 266 & 100 \\
\hline
\end{tabular}


No Quadro 1, os tipos de sujeitos encontrados nos artigos são apresentados em ordem de proximidade à ideia do conceito de sujeito informacional, oposição ao termo usuário da informação. Frisa-se que, em tal quadro, apresenta-se, na coluna "Definição conceitual e emprego do termo", a definição mais presente nos artigos ou a origem identificada do conceito apresentado na coluna Tipo de sujeito. Todavia, nem todos os artigos agrupados na mesma categoria citavam os teóricos listados na definição conceitual: busca-se, então, apenas sintetizar o pensamento mais comum encontrado na maioria dos artigos da mesma categoria.

Quadro 1 - Tipos de empregos do termo sujeito nos periódicos ibero-americanos (2012 a 2018)

\begin{tabular}{|c|c|c|}
\hline $\begin{array}{c}\text { Tipo de sujeito/termo } \\
\text { empregado }\end{array}$ & Definição conceitual e emprego do termo & $\begin{array}{l}\mathrm{N}^{0} \text { de } \\
\text { artigos }\end{array}$ \\
\hline $\begin{array}{l}\text { A) Sujeito } \\
\text { informacional }\end{array}$ & $\begin{array}{l}\text { Emprego do termo, no sentido de oposição ao conceito } \\
\text { de usuário da informação e enquanto forma de entender } \\
\text { a complexidade do fenômeno informacional. Encontra- } \\
\text { se, entre os artigos em estudo, o conceito pioneiro } \\
\text { definidor do sujeito como um agente de informação, } \\
\text { em diversos contextos de conjuntura social e que } \\
\text { assume posição no espaço socioinformacional concreto, } \\
\text { perante a reflexão, análise e atuação na estrutura social } \\
\text { (RENDÓN-ROJAS e GARCÍA CERVANTES, 2012). } \\
\text { Apesar de tal definição ser a primeira registrada do } \\
\text { termo, outra definição teórica é encontrada em mais } \\
\text { dois artigos, um que traz tal definição (ASSIS e MOURA, } \\
\text { 2016) e outro que a cita (SILVA; VECHIATO; VIDOTTI, } \\
\text { 2017). Tal segunda definição é mais específica para o } \\
\text { contexto virtual, segundo a qual o sujeito informacional } \\
\text { é: "sujeito social que manifesta a sua subjetividade } \\
\text { através do estabelecimento de identidades e percursos } \\
\text { informacionais na web. Ele é visto como um sujeito } \\
\text { social pragmático, uma vez que constrói suas relações } \\
\text { pela via da linguagem e do compartilhamento de } \\
\text { significados. Tal fenômeno marca a passagem de um } \\
\text { usuário passivo em busca de recursos que atendam às } \\
\text { suas necessidades de informação para um sujeito ativo } \\
\text { e dinamizador dos fluxos informacionais" (ASSIS e } \\
\text { MOURA, 2013, p. 86). } \\
\text { Outros dois documentos dos periódicos em estudo } \\
\text { empregam o termo sujeito informacional, mas sem } \\
\text { defini-lo teoricamente, um artigo (SANTOS e MONTEIRO, } \\
\text { 2016) e uma entrevista (JÚNIOR, 2015). }\end{array}$ & 5 \\
\hline
\end{tabular}




\begin{tabular}{|c|c|c|}
\hline $\begin{array}{c}\text { Tipo de sujeito/termo } \\
\text { empregado }\end{array}$ & Definição conceitual e emprego do termo & $\begin{array}{l}\mathrm{N}^{0} \text { de } \\
\text { artigos }\end{array}$ \\
\hline $\begin{array}{l}\text { B) Sujeito como } \\
\text { oposição a usuário }\end{array}$ & $\begin{array}{l}\text { Emprego crítico do termo sujeito como forma de } \\
\text { ampliar a consideração de quem lida com a informação } \\
\text { para além da mera satisfação de uma necessidade } \\
\text { de informação (no que se adequaria mais o termo } \\
\text { usuário) para análise de um indivíduo e das "práticas } \\
\text { de informação dos sujeitos em sociedade, cuja atuação } \\
\text { pode ocorrer interativamente em distintos contextos } \\
\text { comunicativos e em rede" (RABELLO, 2013, p. 69). }\end{array}$ & 1 \\
\hline C) Sujeito perfilado & $\begin{array}{l}\text { Emprego do termo sujeito como sinônimo do termo } \\
\text { usuário da informação, aquele que fez ou poderá } \\
\text { fazer uso da informação: "os sujeitos que utilizam a } \\
\text { informação, denominados de usuários da informação" } \\
\text { (ANDRADE; ANDRADE, 2016, p. 105). } 0 \text { artigo } \\
\text { sugere que os estudos de usuários possam ir além } \\
\text { do perfilamento dos usuários, sujeito perfilado, } \\
\text { identificando mais do que perfil econômico e cultural, } \\
\text { mas descrevendo e analisando elementos, "que o } \\
\text { circundam (contexto social e cultural), o complementam } \\
\text { (construções cognitivas e estratégias de busca mentais) } \\
\text { e o constituem (subjetividade de ser sujeito dotado de } \\
\text { consciência)" (ANDRADE; ANDRADE, 2016, p. 113). }\end{array}$ & 1 \\
\hline D) Sujeito social & $\begin{array}{l}\text { Emprego do termo sem definição teórica dele nos } \\
\text { artigos. Com base nos artigos, identifica-se o uso de } \\
\text { sujeito social, em análise de processos de aprendizagem, } \\
\text { e no sentido de indivíduo que interage socialmente com } \\
\text { outros indivíduos e em tal processo interativo aprende e } \\
\text { lida com a informação. }\end{array}$ & 9 \\
\hline $\begin{array}{l}\text { E) Discurso do sujeito } \\
\text { coletivo }\end{array}$ & $\begin{array}{l}\text { Emprego nos artigos, com definição teórica específica, } \\
\text { de método de análise de dados com base na Análise } \\
\text { do discurso do sujeito coletivo, para estudo da } \\
\text { autoexpressão dos sujeitos sem perder a perspectiva } \\
\text { coletiva: "O Discurso do Sujeito Coletivo é, por isso, } \\
\text { uma proposta explícita de reconstituição de um ser } \\
\text { ou entidade empírica coletiva, opinante na forma de } \\
\text { um sujeito de discurso emitido na primeira pessoa do } \\
\text { singular" (LEFĖVRE; LEFĖVRE, 2006, p. 519). }\end{array}$ & 12 \\
\hline $\begin{array}{l}\text { F) Sujeito como } \\
\text { indivíduo na } \\
\text { Biblioteconomia, } \\
\text { Arquivologia e } \\
\text { Museologia }\end{array}$ & $\begin{array}{l}\text { Emprego do termo sujeito em sentido amplo, mas } \\
\text { aplicado ao campo da Ciência da Informação, } \\
\text { especificamente aos subcampos da Biblioteconomia, } \\
\text { Arquivologia e Museologia e com definição teórica: } \\
\text { "usuários, públicos, clientes, utentes - enfim, os sujeitos } \\
\text { que se relacionam, consultam, buscam, visitam e } \\
\text { experimentam os arquivos, as bibliotecas e os museus" } \\
\text { (ARAÚJO, 2013, p. 214). }\end{array}$ & 1 \\
\hline
\end{tabular}




\begin{tabular}{|c|c|c|}
\hline $\begin{array}{c}\text { Tipo de sujeito/termo } \\
\text { empregado }\end{array}$ & Definição conceitual e emprego do termo & $\begin{array}{l}\mathrm{N}^{0} \text { de } \\
\text { artigos }\end{array}$ \\
\hline G) Sujeito informativo & $\begin{array}{l}\text { Emprego do termo, sem definição teórica, como sujeito } \\
\text { informativo, que seria o sujeito que tem direito ao } \\
\text { acesso à informação: "direito primordial do homem que } \\
\text { o fornece a possibilidade de tomada de consciência e } \\
\text { emancipação cívica, política e social” (GOMES, 2016, p. } \\
\text { 18). }\end{array}$ & 1 \\
\hline $\begin{array}{l}\text { H) Modelo argumental } \\
\text { do sujeito }\end{array}$ & $\begin{array}{l}\text { Proposta de um modelo de perfil de usuário de um } \\
\text { site, com base na aplicação do Modelo argumental do } \\
\text { sujeito, com definição teórica específica: métodos que } \\
\text { permitem o acesso ao discurso do sujeito e, assim, } \\
\text { a certos eventos que formam suas percepções da } \\
\text { realidade. Um argumento ou uma estrutura de enredo } \\
\text { seria, nesse sentido, um conjunto de ideias e opiniões } \\
\text { pessoais interligadas, para apoiar e estabelecer a razão } \\
\text { para o desempenho de um comportamento do sujeito } \\
\text { (CALVIÑO, 2012). }\end{array}$ & 1 \\
\hline I) Sujeito-arquivista & $\begin{array}{l}\text { Emprego do termo, sem definição teórica específica, } \\
\text { como sujeito-arquivista, relacionado ao profissional } \\
\text { arquivista, visto como sujeito social inserido socialmente } \\
\text { por meio da linguagem e especificidades de sua prática } \\
\text { profissional (SILVA; ROMÃO, 2012). }\end{array}$ & 1 \\
\hline $\begin{array}{l}\text { J) Sujeito qualificado } \\
\text { (profissional) }\end{array}$ & $\begin{array}{l}\text { Emprego do termo, sem definição teórica, para definir } \\
\text { um sujeito qualificado para exercer uma determinada } \\
\text { prática profissional, como, no caso do artigo } \\
\text { categorizado, o jornalista. }\end{array}$ & 1 \\
\hline $\begin{array}{l}\text { L) Sujeito de forma } \\
\text { genérica/sujeito de } \\
\text { pesquisa }\end{array}$ & $\begin{array}{l}\text { Emprego, sem definição teórica específica, do termo } \\
\text { sujeito no sentido de individuo acerca do qual se fala no } \\
\text { artigo e/ou no sentido de sujeito de pesquisa - indivíduo } \\
\text { abordado, questionado, observado, entrevistado, } \\
\text { analisado etc. no estudo apresentado no artigo. }\end{array}$ & 227 \\
\hline $\begin{array}{l}\text { M) Sujeito fonte e } \\
\text { receptor }\end{array}$ & $\begin{array}{l}\text { Emprego do termo sujeito, sem definição teórica, } \\
\text { para se referir ao indivíduo como fonte e receptor de } \\
\text { informações veiculadas na mídia (matérias jornalísticas). }\end{array}$ & 1 \\
\hline $\begin{array}{l}\text { N) Sujeito } \\
\text { cognoscente }\end{array}$ & $\begin{array}{l}\text { Emprego do termo sujeito cognoscente, sem definição } \\
\text { teórica dele nos artigos. É identificado, com base nos } \\
\text { artigos, o uso de sujeito cognoscente no sentido de um } \\
\text { sujeito detentor de modelos mentais e que realiza um ato } \\
\text { de conhecimento por meio do pensamento. }\end{array}$ & 4 \\
\hline 0) Sujeito da oração & $\begin{array}{l}\text { Emprego do termo, sem definição teórica, para } \\
\text { caracterizar o sujeito no sentido gramatical, o sujeito da } \\
\text { oração em uma sentença. }\end{array}$ & 1 \\
\hline
\end{tabular}

Fonte: autores 
Ao analisar-se os tipos de sujeitos apresentados nos periódicos iberoamericanos em estudo, faz-se algumas interpretações, aplicáveis ao referido contexto. 0 emprego de sujeito mais frequente dentre os artigos em estudo é o de forma genérica, utilizado como sinônimo de indivíduos, sendo comum 0 uso associado com pesquisa, na forma sujeito de pesquisa. Entretanto, em tais artigos, o conceito de sujeito não é problematizado ou definido, tampouco usado como oposição à ideia de usuário da informação ou para demarcar uma perspectiva social da análise em estudos de usuários, assim, acerca do emprego de tal termo sujeito, ele é usado sem incremento conceitual, não agregando conteúdo conceitual ou problematizador.

Nota-se que o termo sujeito informacional, quarto tipo de emprego do conceito de sujeito mais frequente entre os periódicos em avaliação, é ainda muito pouco usado na área, são apenas cinco citações ao termo, enquanto que o termo usuário da informação é empregado em 901 artigos. Além disso, o termo sujeito informacional só é encontrado em periódicos brasileiros, apesar de o primeiro registro do termo, encontrado neste estudo, ser de autoria de pesquisadores mexicanos - em trabalho publicado no Brasil (RENDÓN-ROJAS; GARCÍA CERVANTES, 2012). Constata-se também que, apesar de 0 termo sujeito informacional só ser encontrado em três dos 45 periódicos em avaliação após 2012, Rendón-Rojas e García Cervantes (2012) não são citados ou creditados nas utilizações posteriores do termo, sendo referenciada uma nova definição teórica apresentada por Assis e Moura (2013), referindose ao contexto virtual, conforme mostra o item A do Quadro 1. Em tal definição, para além da questão de ser um sujeito contextualizado na web, parece que o emprego do termo sujeito evoca a um sujeito reflexivo, portanto, não apenas receptor, recipiente, mas, sim, um sujeito pragmático, inserido em um contexto específico e interativo, no qual faz constante uso de uma linguagem e atua frente a um outro sujeito e, somente por isso, por ser entendido enquanto sujeito, em proximidade ao sujeito lacaniano.

Por mais que 0 emprego do termo sujeito informacional seja a problemática central do presente artigo, os textos analisados nos quais o referido termo é usado não permitem avaliação mais aprofundada, por a ideia de sujeito informacional ser apresentada brevemente, sem aprofundamento teórico ou sem ser a discussão central dos cinco artigos aqui encontrados, com exceção do artigo de Réndon-Rojas e García Cervantes (2012).

Assim, como o cerne do conceito de sujeito informacional, os tipos de sujeitos apresentados nos itens B e C do Quadro 1 também trazem oposição à ideia de usuário da informação e sugerem considerar o sujeito para além do momento de uso da informação, ainda que o preposto informacional não seja usado na sequência do termo sujeito, nos supracitados dois itens. A diferença é que no item 
B o termo sujeito é usado para a sugestão de um modo de ir além da busca e uso da informação. Enquanto que no item C o termo sujeito é usado como sujeito perfilado, afirmando que os estudos de usuários no campo da Cl costumam apenas levantar informações demográficas dos sujeitos, sem analisar os contextos e elementos sociais e culturais da informação e dos sujeitos que com ela se relacionam, ideia também imbricada no conceito de sujeito informacional.

No item D, o termo sujeito é apresentado como sujeito social, forma de considerar o sujeito nas pesquisas apresentadas nos artigos assim categorizados e que definem os sujeitos ao lidarem com a informação em processos de aprendizagem e interação social com outros sujeitos e que somente aprendem ao socializarem informações. Ainda que utilizem o termo social associado ao termo sujeito, tal emprego da definição de sujeito não tem ligação direta com o conceito de sujeito informacional nem traz oposição à ideia de usuário, pois, em sua maioria, são artigos que falam sobre a profissão do bibliotecário ou sobre a biblioteca escolar, mas sem irem além de perfis de uso da informação ou do espaço da biblioteca.

Acerca do item E, constata-se que ser ele o segundo tipo mais frequente de emprego do conceito de sujeito nos periódicos em estudo e trata-se da aplicação de um método de análise das informações compartilhadas por sujeitos, especificamente o do discurso dos sujeitos por meio da técnica da análise do discurso coletivo (LEFÈVRE; LEFÈVRE, 2006). Tal aplicação demonstra a preocupação com a perspectiva coletiva das experiências dos sujeitos, focando-se na análise social do fenômeno informacional. Assim, apesar de não se referir diretamente ao conceito de sujeito informacional, a análise do discurso coletivo também privilegia o estudo da coletividade e das relações sociais entre os sujeitos.

Sujeito cognoscente é o quinto tipo de definição de sujeito mais frequente encontrado nos periódicos em questão, no entanto, não se trata de análises entendendo o sujeito desta forma - sujeito que adquire conhecimentos e os agrega ao próprio estado mental -, mas de revisões teóricas acerca dos principais paradigmas do campo da Cl. Em tal contexto, o conceito de sujeito cognoscente é apresentado dentro do paradigma cognitivo da Ciência da Informação - idealista e individualista, entende a informação como sendo interpretada objetivamente e relacionada aos conteúdos intelectuais, e como separada do usuário e existente somente em espaços cognitivos ou mentais (CAPURR0, 2003).

Os demais tipos de empregos do termo sujeito nos artigos em estudo são muito pouco frequentes e a análise sumária deles encontra-se no Quadro 1: F) Sujeito como indivíduo na Biblioteconomia, Arquivologia e Museologia; G) Sujeito informativo; I) Sujeito-arquivista; J) Sujeito qualificado (profissional); M) Sujeito fonte e receptor; 0) Sujeito da oração. 
Se no início, na Grécia Antiga, com Aristóteles (2002), o conceito de sujeito nasce para demarcar a essência do ser, o substrato das pessoas, para além do corpo físico e das experiências do corpo físico, o conceito de sujeito informacional também surge para demarcar a investigação da essência e dos contextos sociais, culturais, simbólicos e econômicos dos sujeitos e de suas relações com a informação no mundo social, ultrapassando a análise do momento de contato/uso com a informação. Se em Lacan (1988) e na psicanálise o sujeito só existe por meio da linguagem e é o efeito do campo da linguagem, na $\mathrm{Cl}$, o sujeito informacional só existe por meio da informação e das relações que ele estabelece com e por meio da informação, sendo tal sujeito o efeito do fenômeno informacional. A ideia abarcada por um sujeito informacional é a de superar o estudo do momento de busca e uso da informação, ampliando a interpretação para o entendimento dos contextos e de como a informação se imbrica na vida dos sujeitos informacionais, promovendo significados e relações com outros sujeitos.

Apresentados e brevemente discutidos os tipos de sujeitos apresentados nos periódicos em análise, traça-se, na sequência, algumas considerações finais pertinentes ao uso do conceito de sujeito informacional em periódicos ibero-americanos do campo da $\mathrm{Cl}$, problemática do presente artigo.

\section{CONSIDERAÇÕES FINAIS}

Após a revisão teórico-conceitual do termo sujeito informacional, bem como do emprego do referido termo em artigos presentes em periódicos científicos ibero-americanos disponíveis no Portal de Periódicos da Capes, além da avaliação de usos diversos do termo sujeito e do emprego do termo usuário da informação, apresenta-se algumas considerações finais sobre tais empregos no contexto da pesquisa.

Inicialmente, percebe-se que o termo sujeito informacional surge em forma similar à que 0 termo sujeito ganhou força no pensamento científico moderno - para buscar solucionar uma angústia científica e teórica, em meio à busca por um novo entendimento dos indivíduos e de suas relações com o mundo e com outros indivíduos, em contextos e experiências mais complexas em relação a períodos históricos anteriores, dado que os termos vigentes não mais davam conta conceitualmente de abarcar a complexificação das novas experiências e relações sociais vigentes.

No campo da $\mathrm{Cl}$, o conceito de sujeito informacional parece surgir quando pesquisadores da área, em especial do subcampo dos estudos de usuários, percebem que o termo usuário da informação não se adequava às teorias e aos métodos para estudo das pessoas, considerando mais do que: 
busca e uso da informação, perfis demográficos de quem usa a informação; e/ou a mera satisfação de uma necessidade informacional. A referida angústia em relação à insuficiência ou inadequação do termo usuário da informação, para entendimento de cenários cada vez mais intricados no mundo contemporâneo, ganha força com a emergência do paradigma social da Cl - compreende a informação em contextos sociais e materiais humanos, com foco na interação entre os usuários da informação (CAPURR0, 2003).

Sob tal prisma, o termo usuário, basicamente, quem usa a informação, não parecia pertinente a estudos em uma perspectiva social, focada em entender os contextos socioinformativos, considerando os elementos sociais, culturais e históricos das relações sociais de quem cria, compartilha e se apropria, em suma, lida com a informação de diversas formas. Isso se dá porque tais estudos objetivam entender quais significados são construídos a partir da informação e qual papel a informação ocupa de forma dinâmica na vida dos sujeitos. Assim, o termo sujeito informacional é uma tentativa de aproximar os estudos da $\mathrm{Cl}$ de um entendimento mais holístico da complexidade social e relacional dos sujeitos com o fenômeno informacional, considerando 0 antes, 0 durante e 0 depois do contato com a informação.

Apesar da referida angústia no campo da $\mathrm{Cl}$, percebe-se a predominância do emprego do termo usuário da informação nos artigos ibero-americanos investigados - encontra-se 901 artigos com tal emprego, contra somente cinco com o emprego do termo sujeito informacional, sendo que, dos cinco, apenas dois são estudos de usuários, ambos no contexto virtual, com a perspectiva mais ampla sugerida pelo conceito de sujeito informacional. 0 pouco uso pode ser visto sem grande alarde, por se tratar de termo ainda novo no campo, pois o primeiro registro dele, localizado pelo presente artigo, data de 2012. Mas, ao mesmo tempo, pode evidenciar pouca preocupação com novas formas de se compreender 0 fenômeno informacional para além de perfis de uso e/ou de perfis demográficos de quem se relaciona com a informação. Não que somente estudos que se apropriem do conceito de sujeito informacional busquem uma perspectiva social e mais ampla de análise dos estudos de usuários, entretanto, assumir a perspectiva do conceito demarca uma busca maior por um aprofundamento analítico. Além disso, a questão torna-se complexa, pois há, por vezes, estudos que buscam uma nova forma de compreensão de quem lida com a informação, buscando ampliar o olhar, mas ainda assim optam pelo emprego do termo usuário e, da mesma forma, há estudos que podem utilizar o termo sujeito informacional, mas sem fazer, de fato, uma análise do contexto e da perspectiva social, contextual e cultural da relação social do sujeito com a informação. 
Destarte, faz-se importante frisar que, dentro, obviamente, do universo pesquisado, os artigos que compõem o corpo do presente artigo, o termo sujeito informacional pode ser entendido como um termo ibero-americano, pois parece ser sugerido inicialmente por pesquisadores do México (RENDÓNROJAS; GARCÍA-CERVANTES, 2012), mas que, conforme os dados deste estudo, parece que só é adotado por cientistas brasileiros. Talvez, por sua origem ibero-americana, o termo ainda não seja tão usual, pois se constata a predominância de periódicos estadunidenses dentre os 399 periódicos do campo da Cl presentes no referido portal - 45,61\% ou 182 de 399 periódicos são publicados nos Estados Unidos. Diz-se isso por ser reconhecido o maior impacto de visões estadounidentes a anglosaxãs do fenômeno informacional no campo mundial da Cl.

De forma mais ampla, além do emprego do termo sujeito informacional, demarca-se também que a apropriação mais comum do termo sujeito se dá em um emprego como mero sinônimo de indivíduo de pesquisa, sujeito o qual se investiga ou que fornece dados em uma coleta de dados científica. Além disso, aponta-se que o uso do termo sujeito nos periódicos em estudo faz-se, em geral, sem reflexão ou problematização teórica, que, por sua vez, caso ocorresse, poderia contribuir para os estudos realizarem investigações para além do uso e/ou da necessidade da informação.

Acerca de como operacionalizar na pesquisa a análise do sujeito informacional, para conseguir se aproximar da complexidade holística do referido sujeito, não há um modelo ou percurso único, 0 pesquisador precisará valer-se de criatividade científica, baseando-se na triangulação tanto de técnicas de coletas de dados quanto de teorias para leitura dos dados, de forma a permitir capturar o sujeito e sua relação intricada com o fenômeno informacional, priorizando técnicas e teorias que evidenciem os contextos e as contradições. Portanto, considerar o sujeito (ou o antes tido como usuário) enquanto sujeito informacional é uma ação dupla de pesquisa: a ação de assumir a perspectiva informacional de estudo do sujeito e a ação de buscar entender a perspectiva informacional da vida social e das relações do sujeito investigado.

Com isso, empregar o termo sujeito informacional nas pesquisas e nos estudos de usuários não significa simplesmente trocar usuário (da biblioteca, do site, do sistema, do arquivo etc.) ou público ou cliente (dos museus) por sujeito informacional. A mudança não é meramente do termo, mas, sim, da perspectiva de pesquisa e do entendimento de quem se relaciona com a informação, nos mais diversos espaços, contextos e formatos, físicos e/ou virtuais. A perspectiva do sujeito informacional é a de uma busca pela compreensão de todo o processo da relação socioinformativa dos sujeitos, considerando, em especial, os contextos, em vez de um foco somente em um momento recortado de 
uso, de contato físico e/ou virtual com a informação. E é pelo foco nos contextos e relações que a ideia de sujeito informacional parece se adequar melhor à perspectiva das práticas informacionais e não à da tipificação de ações, comum nos estudos de comportamentos informacionais.

Contudo, ressalta-se que o estudo do emprego do termo sujeito informacional na IberoAmérica necessita de um aprofundamento maior do que o realizado no presente estudo exploratório, investigando, por exemplo, periódicos de todos 24 países da Ibero-América não presentes no Portal de periódicos da Capes, no qual constam publicações de apenas nove dos países. Por isso, o pouco uso do conceito de sujeito informacional nos periódicos ibero-americanos não significa, necessariamente, pouco uso do termo na Ibero-América em geral, tampouco no campo mundial da Cl. Há de se estudar outros periódicos ibero-americanos e mundiais, para se analisar o emprego do sujeito informacional, 0 que fica como sugestão para futuras investigações.

Os resultados do presente estudo parecem indicar que sujeito informacional se trata de um termo ainda recém-emergido, cujo pouco uso tem uma adequação inversamente proporcional à sua aplicação ao estudo das complexidades contemporâneas das questões socioinformativas.

\section{REFERÊNCIAS}

ANDRADE, Robéria de Lourdes de Vasconcelos; ANDRADE, Wendia Oliveira de. Usuários da informação: sujeitos perfilados com base na Ciência da Informação. Revista Conhecimento em Ação, Rio de Janeiro, v. 1, n. 1, p. 105-114, jan./jun. 2016. Disponível em: https://revistas.ufrj.br/index.php/ rca/article/view/2875/2788. Acesso em 6 jun. 2018.

ARAÚJ0, Carlos Alberto Ávila. Em questão, Porto Alegre, v. 19, n.1, p. 213-238, jan./jun. 2013. Disponível em: http://www.seer.ufrgs.br/index.php/EmQuestao/article/view/37518/31551. Acesso em: 5 jun. 2018.

ARAÚJO, Carlos Alberto Ávila. Estudos de usuários: uma abordagem na linha ICS. In: REIS, Alcenir Soares dos; CABRAL, Ana Maria Resende (org.). Informação cultura e sociedade: interlocuções e perspectivas. Belo Horizonte: Novatus, 2007.

ARAÚJ0, Carlos Alberto Ávila. Existe um pensamento informacional ibero-americano. Logeion: filosofia da informação, Rio de Janeiro, v. 4, n. 2, p. 31-55, 2018. Disponível em: http://revista.ibict. br/fiinf/article/view/4212. Acesso em: 3 jun. 2018.

ARAÚJO, Carlos Alberto Ávila. 0 sujeito informacional no cruzamento da Ciência da Informação com as Ciências Sociais. XIV, ENANCIB, 2013, Florianópolis, SC. In: XIV Encontro Nacional de Pesquisa em Ciência da Informação, 14. , 2013, Florianópolis, SC. Anais... Florianópolis, SC: XIV ENANCIB, 2013. Disponível em: http://enancib.sites.ufsc.br/index.php/enancib2013/XIVenancib/paper/ viewFile/142/263. Acesso em: 01 nov. 2013. 
ARISTÓTELES. Metafísica. São Paulo: Edições Loyola, 2001.

ASSIS, Juliana de; MOURA, Maria Aparecida. Folksonomia: a linguagem das tags. Encontros Bibli: revista eletrônica de biblioteconomia e ciência da informação, Florianópolis, v. 18, n. 36, p. 85106, jan./abr. 2013. Disponível em: https://periodicos.ufsc.br/index.php/eb/article/view/24015/0. Acesso em: 6 jun. 2018.

BARROSO, Adriane de Freitas. Sobre a concepção de sujeito em Freud e Lacan. Barbarói, Santa Cruz do Sul, n. 36, p. 149-159, jan./jun. 2012. Disponível em: http://pepsic.bvsalud.org/scielo. php?script=sci_arttext\&pid=S0104-65782012000100009. Acesso em: 2 jun. 2018.

CALVIÑO, Manuel. Siempre hay argumentos. Editorial Caminos, 9 maio 2012. Disponível em: https:// ecaminos.org/article/siempre-hay-argumentos/. Acesso em: 5 jun. 2018.

CAPURR0, Rafael. Epistemologia e Ciência da Informação. In: ENCONTRO NACIONAL DE PESQUISA EM CIÊNCIA DA INFORMAÇÃO, 5., Belo Horizonte, MG, 2003. Anais... Belo Horizonte: ENANCIB, 2003. Disponível em: http://www.capurro.de/enancib_p.htm. Acesso em 10 jan. 2009.

DAY, Ronald E. Death of the user: reconceptualizing subjects, objects, and their relations. Journal of the American Society for Information Science and Technology, Silver Spring, v. 62, n. 1, p. 78-88, 2011. Disponível em: http://onlinelibrary.wiley.com/doi/10.1002/asi.21422/epdf. Acesso em: 11 jul. 2017.

DAY, Ronald E. Indexing it all: the modern documentary subsuming of the subject and its mediation of the real. IX, ICONFERENCE, 2014, Berlim. Germany. In: iConference 2014, 9, 2014, Berlim, Germany. Anais... Berlim, Germany: IV ICONFERENCE, 2014. Disponível em: https://www.ideals.illinois.edu/ bitstream/handle/2142/47318/140_ready.pdf?sequence=2. Acesso em: 11 jul. 2017.

DESCARTES, René. Descartes. São Paulo: Abril Cultural, 1979.

DESCARTES, René. Discurso do método. São Paulo: Martins Fontes, 2001.

DUARTE, Adriana Bogliolo Sihiral; ARAÚJO, Carlos Alberto Ávila; PAULA, Cláudio Paixão Anastácio de. Práticas informacionais: desafios teóricos e empíricos de pesquisa. In: ENCONTRO INTERNACIONAL DE ESTUDO DE USOS E USUÁRIOS DA INFORMAÇÃO - ENEU, 1., 2017, Fortaleza. Anais... Fortaleza: Universidade Federal do Ceará, 2017.

ELIA, Luciano. 0 conceito de sujeito. Rio de Janeiro: Jorge Zahar Editor, 2010.

FREIRE, Bernadina Maria Juvenal; AQUINO, Mirian de Albuquerque. Ciência da Informação: buscando abrigo para um sujeito. TransInformação, Campinas, v. 12, n. 2, p. 71-79, jul./dez. 2000. Disponível em: http://periodicos. puc-campinas.edu.br/seer/index.php/transinfo/article/view/1532/1506. Acesso em: 11 jul. 2017.

GOMES, Amanda. Lei de acesso à informação: 0 cidadão enquanto sujeito informativo. Biblos: Revista do Instituto de Ciências Humanas e da Informação, v. 30, n.2, P. 5-21, 2016. Disponível em: https:// periodicos.furg.br/biblos/article/view/5635/4434. Acesso em: 5 jun. 2018. 
HERNÁNDEZ-PACHECO, Javier. Hypokeimenon: origen y desarrollo de la tradición filosófica. Madri: Ediciones Encuentro, 2003.

JÚNIOR, Oswaldo Francisco de Almeida. Entrevista: Oswaldo Francisco de Almeida Júnior. InCID:

Revista de Ciência da Informação e Documentação, Ribeirão Preto, v. 7, n. 1, p. 201-217, mar./ago. 2016. Disponível em: http://www.revistas.usp.br/incid/article/view/113824/111696. Acesso em: 6 jun. 2018.

KANT, Immanuel. Escritos. Rio de Janeiro: Jorge Zahar Editor, 1998.

LACAN, Jacques. 0 seminário - livro 11: os quatro conceitos fundamentais da psicanálise. Rio de Janeiro: Jorge Zahar Editor, 1988.

LE COADIC, Yves-François. A ciência da Informação. Brasília: Briquet de Lemos/Livros, 1996.

LEFÈVRE, Fernando; LEFÈVRE, Ana Maria Cavalcanti. 0 sujeito coletivo que fala. Interface: comunicação, saúde, educação, v. 10, n. 20, p. 517-24, jul./dez. 2006. Disponível em: http://www. scielo.br/pdf/icse/v10n20/17.pdf. Acesso em: 5 jun. 2018.

NÚÑEZ PAULA, Israel. Las necessidades de información y formación: perspectivas socio-psicológica e informacional. Acimed, Cuba, v. 12, n. 5, set./out. 2004. Disponível em: http://bvs.sld.cu/revistas/ aci/vol12_5_04/aci04504.htm. Acesso em: 10 jan. 2010.

OEl. 0 que é a OEl?. Organização dos estados ibero-americanos, 2018. Disponível em: http://www. oei.org.br/oei. Acesso em: 3 jun. 2018.

ORTEGA, Cristina Dotta. Ciência da Informação: do objetivo ao objeto. XIII, ENANCIB, 2012, Rio de Janeiro, RJ. In: XII Encontro Nacional de Pesquisa em Ciência da Informação, 13. , 2012. Anais... Rio de Janeiro, RJ: XIII ENANCIB, 2013. Disponível em: http://repositorios.questoesemrede.uff.br/ repositorios/bitstream/handle/123456789/1089/0RTEGA.pdf?sequence=1. Acesso em: 111 jul. 2017.

PILETTI, José Jobson de A.. PILETTI, Nelson. Toda a história: história geral e do Brasil. São Paulo: Ática, 2007.

PINHEIRO, Lena Vânia Ribeiro. Usuários - informação: o contexto da ciência e da tecnologia. Rio de Janeiro: IBICT, 1982.

PINTO, Flávia Virgínia Melo; ARAÚJO, Carlos Alberto Ávila. Contribuição ao campo de usuários da informação: em busca dos paradoxos das práticas informacionais. TransInformação, Campinas, v. 24, n. 3, p. 219-226, set./dez. 2012. Disponível em: http://periodicos.puc-campinas.edu.br/seer/index. php/transinfo/article/download/1204/1179. Acesso em: 11 jul. 2017.

PREUS, Anthony. Historical dictionary of ancient Greek philosophy. Plymouth: The Scarecrow Press, 2007.

RABELLO, Rodrigo. Noções de sujeito em modelos teóricos na ciência da informação: do enfoque no sistema à consideração da agência em contexto. Informação \& Sociedade, João Pessoa, v. 23, n. 3, p. 57-71, set./dez. 2013. Disponível em: http://eprints.rclis.org/23028/1/Rabello_2013_ No\%C3\%A7\%C3\%B5es\%20de\%20sujeito.pdf. Acesso em: 5 jun. 2018. 
RENDÓN-ROJAS, Miguel Ángel; GARCÍA CERVANTES, Alejandro Luis. El sujeto informacional en el contexto contemporáneo. Un análisis desde la epistemología de la identidad comunitariainformacional. Encontros Bibli: revista eletrônica de biblioteconomia e ciência da informação, Florianópolis, v. 17, n. 33, p. 30-45, jan./abr. 2012.

RENDÓN-ROJAS, Miguel Ángel; HERRERA DELGADO, Lizbeth Berenice. Bases filosóficas de la organización de la información. Perspectivas em Ciência da Informação. Belo Horizonte, v. 15, n. 1, p. 3-17, 2010.

SANTOS, Miriam Cristina Fava; MONTEIRO, Silvana Drumond. Interfaces como metacomunicação: contribuição da engenharia semiótica na representação no ciberespaço. Informação \& Informação, Londrina, v. 21, n. 1, p. 80 - 102, jan./abr. 2016.

SAVOLAINEN, Reijo. Information behavior and information practice: reviewing the "umbrella concepts" of information-seeking studies. Library Quarterly, Chicago, v. 77, n. 2, p. 109-132, 2007.

SEGIB. Quem somos. Secretaria-geral Ibero-Americana, 2018. Disponível em: https://www.segib.org/ pt-br/quem-somos/. Acesso em: 3 jun. 2018.

SILVA, Jonathan Raphael Bertassi da; ROMÃO, Lucília Maria Sousa. Sobre arquivos e trincheiras: a batalha implícita do sujeito-arquivista em Brazil, o filme. DataGramaZero, v. 13, n. 6, p. A01, 2012.

SILVA, Nathália Britto Pinheiro da; VECHIATO, Fernando Luiz; VIDOTTI, Silvana Aparecida Borsetti Gregorio. Encontrabilidade da informação no Ambiente technology, entertainment and design.

Informação \& Informação, Londrina, v. 22, n. 2, p. 481 - 496, maio/ago. 2017.

SUJEITO. In: Grande Enciclopédia Larousse Cultural. São Paulo: Nova Cultural, 1998. V. 22. p. 5529. 